\title{
A comparative study of nuclear form factor, area and diameter in non-Hodgkin's lymphomas and reactive lymph nodes
}

\author{
J CROCKER, EL JONES, RC CURRAN
}

From the Department of Pathology, The Medical School, University of Birmingham, Birmingham, B15 2TJ

SUMMARY The mean nuclear area, maximum nuclear diameter $\left(\mathrm{D}_{\max }\right)$ and form factor (FF) $\dot{\omega}_{\sigma}$ have been measured in 30 specimens of non-Hodgkin's lymphoma (NHL) and 10 reactive lymph $\dot{\omega}$ nodes, using the Reichert-Jung (Kontron) $\mathrm{MOP}-\mathrm{AMO}_{3}$ image analyzer. Nuclear area and $\mathrm{D}_{\max } \mathbb{C}_{\infty}$ were found to be greater in high-grade NHL than in low-grade lymphomas and reactive nodes. In ${ }_{0}$ addition, there was close correlation between nuclear area and $D_{\max }$, especially for low-grade ${ }_{-}^{\supset}$ NHL and reactive specimens. As a means of distinguishing between high- and low-grade lym- $\bar{z}$ phomas, however, the FF appears to be of little value.

We have previously measured ${ }^{1}$ the nuclear maximum diameter $\left(D_{\max }\right)$ in a series of specimens of non-Hodgkin's lymphomas (NHL). High-grade NHL were found to have greater values for nuclear $D_{\max }$ than low-grade lymphomas. As an extension of this study we have determined the $D_{\max }$ in a larger series of NHL, including in addition specimens of reactive lymph nodes. We have also simultaneously measured the mean nuclear area and form factor (FF) in these specimens. The FF value of a structure provides a useful measure of its shape ${ }^{23}$ and was considered to be of interest in relation to nuclei in NHL, perfectly round nuclei having an FF value of 1.0 and irregular nuclei having FF values deviating from unity.

\section{Material and methods}

\section{LYMPH NODES}

Forty lymph nodes were examined, from the same number of patients. Prior to measurement of nuclear $\mathrm{D}_{\max }$, area and FF, the specimens of NHL were diagnosed according to the Kiel classification; 4 these specimens, together with the reactive lymph nodes, were coded by number, all measurements being performed "blind". There were 6 centrocytic, 9 centrocytic-centroblastic, 2 . centroblastic, 9 immunoblastic, 2 lymphoblastic and 2 high-grade unclassifiable lymphomas. Ten specimens of lymph nodes exhibiting "reactive" hyperplasia were also examined (Tables 1 and 2).

Accepted for publication 20 October 1982
FIXATION AND STAINING

These were performed as described before; ${ }^{\prime}$ the nodes were obtained immediately following surgicalo excision and were cut into $2 \mathrm{~mm}$ thick slices. These were then fixed for $24 \mathrm{~h}$ in $10 \%$ formol saline, pro-음 cessed to paraffin wax, sectioned at $4 \mu \mathrm{m}$ andoำ stained by Harris's haematoxylin and eosin. The sec-@ tions were then dehydrated, cleared and mounted in $\overrightarrow{\overrightarrow{0}}$ balsam.

\section{NUCLEAR MEASUREMENTS}

We have previously described the use of the MOP- $\mathrm{AMO}_{3}$ in detail;: 3567 the machine was used: in conjunction with a light microscope and a camera 3 lucida drawing tube situated above a graphic tablet. The images of nuclei were outlined by a sensitive $\frac{0}{3}$ pen attached to the microprocessor of the MOP-o $\mathrm{AMO}_{3}$. For each specimen, 500 nuclei were measured, the values of $D_{\max }$, area and FF for each nuc $-\frac{D}{O}$ leus being stored simultaneously on a separate channel in the microprocessor. Thus, three channels were used, one for each parameter measured. ToN enable accurate outlining of nuclei the sections were స్ examined under a $100 \times$ oil-immersion lens during the measurement procedure. For each field examined, all nuclei other than those of endotheliaf cells, fibroblasts and polymorphonuclear leucocytes were measured. Fields were selected randomly, the first field examined being that which first fell under the microscope lens when the slide was placed on the microscope stage. Adjacent fields were then $\frac{O}{\mathbb{D}}$ examined, moving from left to right.

In the case of follicular NHL or of specimens of 
Table 1 Reactive lymph nodes and low grade NHL

\begin{tabular}{|c|c|c|c|}
\hline Histological type & Mean nuclear $D_{\max }(\mu m)$ & Mean nuclear area $\left(\mu m^{2}\right)$ & Mean FF \\
\hline Reactive node & $\begin{array}{r}9.7(1.8) \\
9.9(1.6) \\
10.1(2.1) \\
10.3(2.0) \\
10.5(1.7) \\
10.8(1.9) \\
10.9(2.0) \\
11.3(2.1) \\
11.4(1.8) \\
11.8(2.2)\end{array}$ & 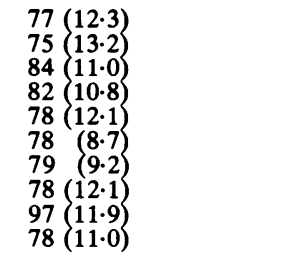 & $\begin{array}{l}0.9(0.1) \\
0.9(0.1) \\
0.8(0.1) \\
0.9(0.2) \\
0.9(0.1) \\
0.8(0.2) \\
0.9(0.1) \\
0.8(0.1) \\
0.8(0.2) \\
0.8(0.1)\end{array}$ \\
\hline Centrocytic lymphoma & $\begin{array}{r}9.9(1.7) \\
10 \cdot 3(1.7) \\
10.6(2.2) \\
10.8(2 \cdot 1) \\
11.0(2 \cdot 0) \\
11.7(2.3)\end{array}$ & 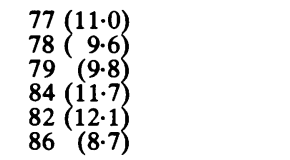 & $\begin{array}{l}0.9(0.1) \\
0.9(0.2) \\
0.8(0.1) \\
0.8(0.1) \\
0.8(0.1) \\
0.8(0.2)\end{array}$ \\
\hline $\begin{array}{l}\text { Centrocytic-centroblastic } \\
\text { lymphoma }\end{array}$ & $\begin{array}{l}11.0(2.0) \\
11.5(2.1) \\
12.0(2.3) \\
12.1(3.1) \\
12.2(1.8) \\
12.3(1.9) \\
12.4(2.1) \\
12.5(3.1) \\
13.5(2.6)\end{array}$ & $\begin{array}{r}95(13 \cdot 2) \\
97(13 \cdot 6) \\
109(14 \cdot 1) \\
110(12 \cdot 2) \\
110(13 \cdot 9) \\
117(13 \cdot 9) \\
115(14 \cdot 1) \\
120(12 \cdot 6) \\
119(15 \cdot 0)\end{array}$ & $\begin{array}{l}0.9(0.1) \\
0.9(0.1) \\
0.8(0.2) \\
0.8(0.1) \\
0.8(0.1) \\
0.8(0.1) \\
0.8(0.2) \\
0.8(0.2) \\
0.8(0.1)\end{array}$ \\
\hline
\end{tabular}

Standard deviations are shown in parentheses

Table 2 High-grade $N H L$

\begin{tabular}{|c|c|c|c|}
\hline Histological type & Mean nuclear $D_{\max }(\mu m)$ & Mean nuclear area $\left(\mu^{2}\right)$ & Mean $F F$ \\
\hline Centroblastic lymphoma & $\begin{array}{l}16 \cdot 2(4 \cdot 2) \\
17 \cdot 3(6 \cdot 1)\end{array}$ & $\begin{array}{l}219(14 \cdot 6) \\
220(15 \cdot 1)\end{array}$ & $\begin{array}{l}0.8(0.1) \\
0.7(0.1)\end{array}$ \\
\hline Immunoblastic lymphoma & $\begin{array}{l}19 \cdot 2(6 \cdot 7) \\
20 \cdot 2(7 \cdot 1) \\
20 \cdot 5(5 \cdot 2) \\
20 \cdot 6(4 \cdot 9) \\
21 \cdot 1(6 \cdot 6) \\
22 \cdot 0(6 \cdot 2) \\
23 \cdot 5(5 \cdot 6) \\
23 \cdot 8(5 \cdot 1) \\
25 \cdot 5(5 \cdot 9)\end{array}$ & $\begin{array}{l}260(17 \cdot 1) \\
428(18 \cdot 6) \\
431(19 \cdot 7) \\
441 \\
432(19 \cdot 1) \\
488(17 \cdot 9) \\
472(17 \cdot 0) \\
501(18 \cdot 9) \\
497(17 \cdot 8)\end{array}$ & $\begin{array}{l}0 \cdot 7(0 \cdot 2) \\
0 \cdot 8(0 \cdot 2) \\
0 \cdot 8(0 \cdot 1) \\
0 \cdot 8(0 \cdot 1) \\
0.7(0 \cdot 1) \\
0 \cdot 7(0 \cdot 2) \\
0 \cdot 8(0 \cdot 2) \\
0.7(0 \cdot 2) \\
0.7(0 \cdot 1)\end{array}$ \\
\hline Lymphoblastic lymphoma & $\begin{array}{l}15.0(4 \cdot 3) \\
16.4(4.9)\end{array}$ & $\begin{array}{l}245(16 \cdot 2) \\
225(15 \cdot 8)\end{array}$ & $\begin{array}{l}0.9(0.1) \\
0.9(0.2)\end{array}$ \\
\hline Unclassifiable lymphoma & $\begin{array}{l}19.2(6 \cdot 1) \\
19.7(6 \cdot 5)\end{array}$ & $\begin{array}{l}271(17 \cdot 0) \\
281(16 \cdot 2)\end{array}$ & $\begin{array}{l}0.5(0.2) \\
0.6(0.2)\end{array}$ \\
\hline
\end{tabular}

Standard deviations are shown in parentheses

reactive follicular hyperplasia, care was taken to measure nuclei from the follicles and interfollicular areas in approximately equal proportions.

At the end of the measurement procedure, the data from each channel of the MOP- $\mathrm{AMO}_{3}$ were printed, giving values for median and mean $D_{\max }$, area and FF for each specimen.

As described previously, ${ }^{1}$ the microprocessor was programmed to exclude nuclei with a $D_{\max }$ of $<5$ $\mu \mathrm{m}$; similarly nuclei with an area of $<50 \mu \mathrm{m}^{2}$ were excluded. Correction for section thickness was performed using Weibel curves as described by Steer. ${ }^{8}$ The spherical truncation effect resulting from non- equatorial slicing of nuclei was reduced by excluding nuclei with a $D_{\max }$ of $<5 \mu \mathrm{m}$ and an area of $<50$ $\mu \mathrm{m}^{2}$. However, a correction factor of $1 \cdot 1 \times$ the data was calculated, assuming a minimum measurable $\mathrm{D}_{\max }$ of $5 \mu \mathrm{m}$ and nuclear area of $50 \mu \mathrm{m}^{2}$ and maximum $\mathrm{D}_{\max }$ in the region of $20 \mu \mathrm{m}$ and maximum nuclear area approximately to $600 \mu \mathrm{m}^{2}$.

\section{Results}

Figures 1-3 show the mean values for $D_{\max }$, nuclear area and FF, respectively, for each specimen studied. Reactive lymph nodes have values for $D_{\max }$ 


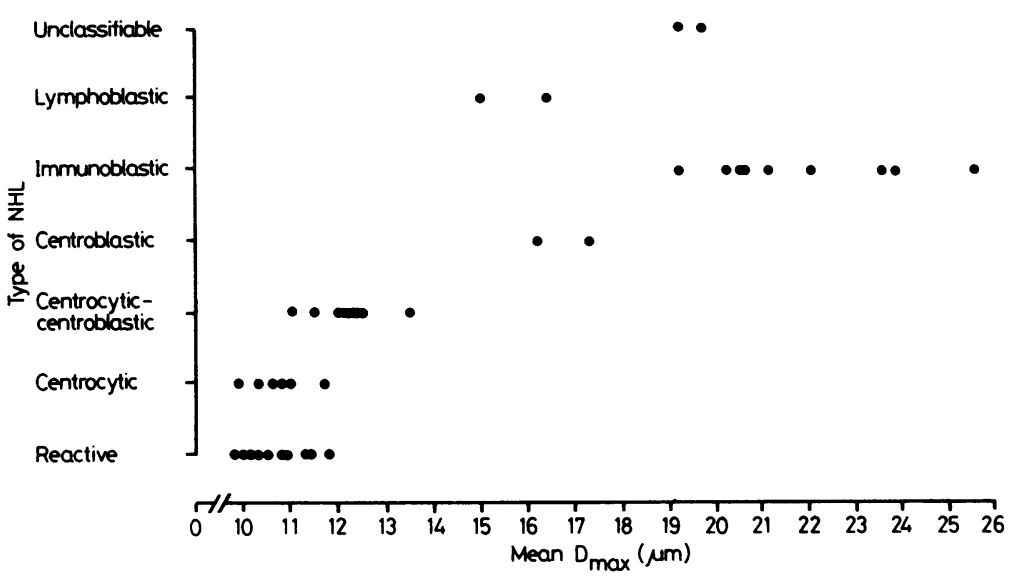

Fig. 1 The mean nuclear $D_{\max }$ for the specimens of $N H L$ and reactive lymph nodes.

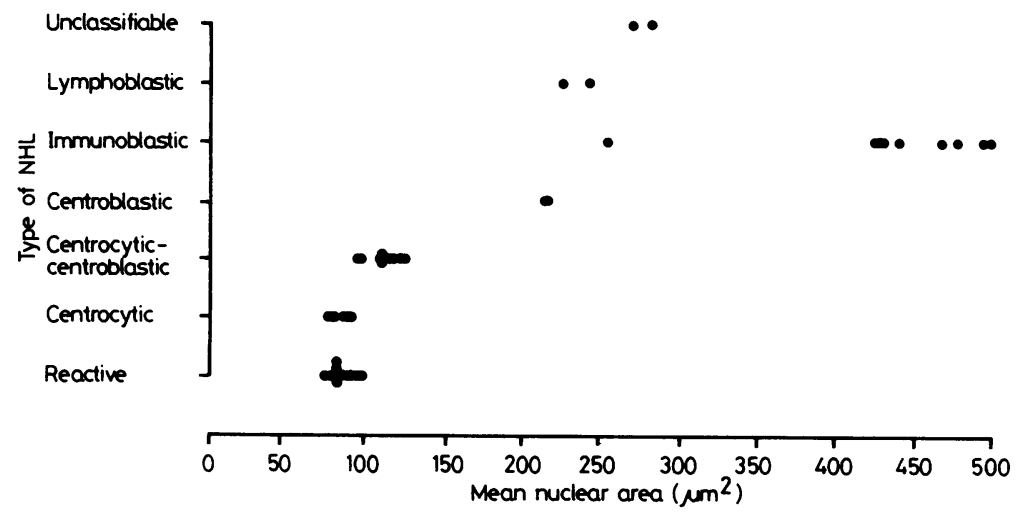

Fig. 2 The mean nuclear area for the specimens of $N H L$ and reactive lymph nodes.
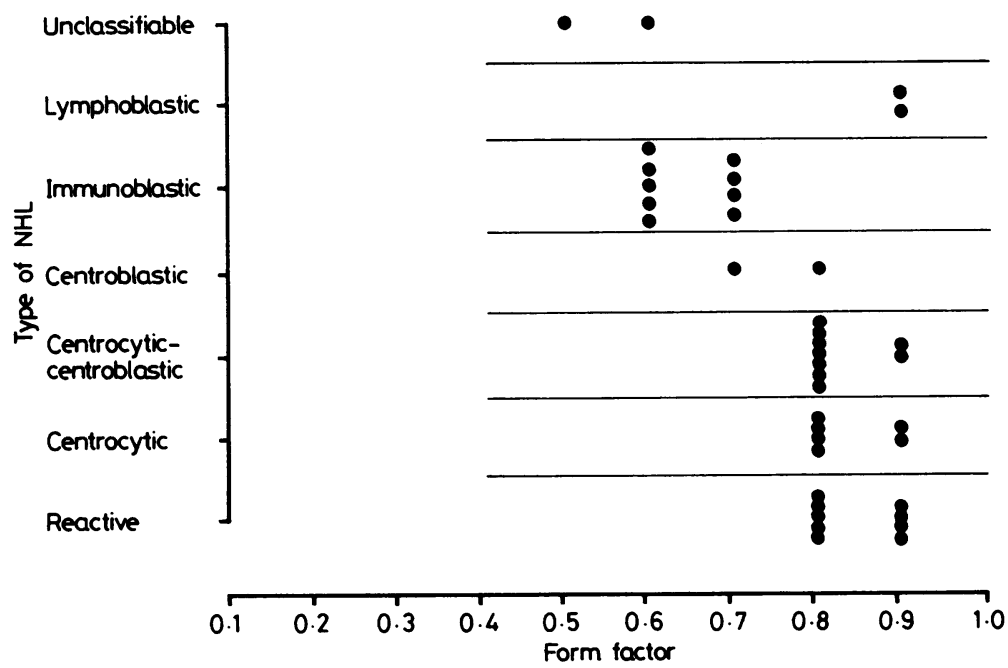

Fig. 3 The mean values of FF for the specimens of $N H L$ and reactive lymph nodes. 


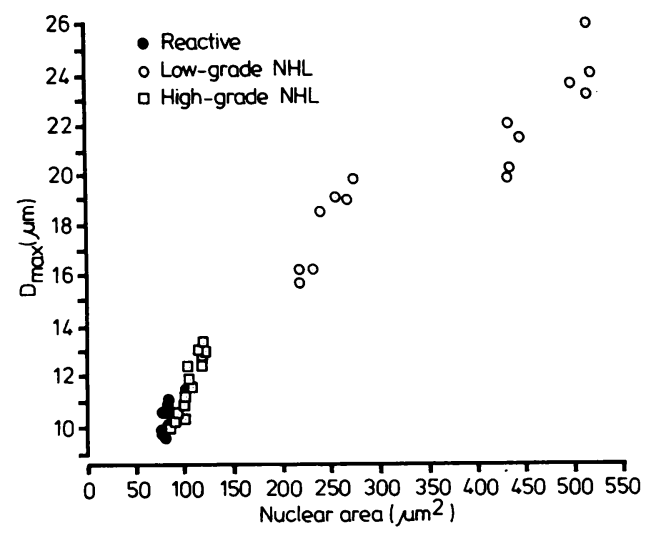

Fig. 4 Mean nuclear $D_{\max }$ for each specimen plotted against mean nuclear area. There is good correlation for all specimens, especially in low-grade $N H L$ and reactive nodes.

ranging from $9.7 \mu \mathrm{m}$ to $11.8 \mu \mathrm{m}$ and values for area ranging from $75 \mu \mathrm{m}^{2}$ to $97 \mu \mathrm{m}^{2}$; FF values of 0.8 and 0.9 were found for all of these nodes. The mean $D_{\max }$ for low-grade NHL ranges from $9.9 \mu \mathrm{m}$ and $13.5 \mu \mathrm{m}$, and their nuclear area measures from 77 $\mu \mathrm{m}^{2}$ to $120 \mu \mathrm{m}^{2}$ whilst the FF values are from 0.8 to 0.9 . High-grade lymphomas have a mean $D_{\max }$ of 15 $\mu \mathrm{m}$ to $25.5 \mu \mathrm{m}$ and nuclear area ranging from 219 $\mu \mathrm{m}^{2}$ to $501 \mu \mathrm{m}^{2}$; their nuclear FF ranges from 0.5 to 0.9 .

The values of $D_{\max }$ and nuclear area for reactive nodes, centrocytic and centrocytic-centroblastic lymphomas are similar, as are the FF values in these specimens. However, centroblastic lymphomas and especially immunoblastic and high-grade unclassifiable NHL have greater values of $D_{\max }$ and nuclear area. The two specimens of lymphoblastic lymphoma have the lowest $D_{\max }$ and nuclear area of the high-grade lesions; also, their nuclei are clearly more round than those of the other types of highgrade NHL (Tables 1 and 2).

Figure 4 shows the values of mean nuclear $D_{\max }$ plotted against mean nuclear area for the 40 specimens. There is very good correlation between these values for the reactive nodes $(r=0.99)$ and lowgrade lymphomas $(r=0.92)$. Nuclear $D_{\max }$ and area show slightly less close correlation in high-grade NHL $(r=0.89)$.

\section{Discussion}

Automatic or semiautomatic morphometric techniques using image analyzers have been used to study lymphomas with interesting results in the past. Crocker and Curran' used a fully automatic image analyzer, the Zeiss "Microvideomat" to study nuclear diameters in imprint preparations of reactive nodes, NHL and Hodgkin's disease, but obtained rather poor separation of measurements between these conditions. In a subsequent study, ${ }^{1}$ we used the Reichert-Jung (Kontron) $\mathrm{MOP}-\mathrm{AMO}_{3}$, an interactive user-controlled image-analyzer to measure $D_{\max }$ in a series of 21 cases of high- and lowgrade NHL. This device enabled the use of conventional paraffin sections rather than imprints. Highgrade NHL were found to have greater values for $D_{\max }$ than low-grade lymphomas. Cumulative probability plots of these data were also used to demonstrate two populations of cells (by virtue of their $D_{\max }$ values) in all of the nodes examined. The relative usefulness of the user-controlled ("interactive") image analyzer was compared with that of fully automatic machines.

Abbott, Blewitt and Bird ${ }^{10}$ used the MOP- $\mathrm{AMO}_{3}$ and Quantimet 720 image analyzers to measure nuclear areas in a small number of specimens (classified according to the scheme of Bennett et al ${ }^{11}$ ). The nuclear area for each specimen appeared to correlate with its histological type. Problems were encountered with the Quantimet 720, much light-pen editing proving to be necessary for the measurement procedure.

We have extended our previous study of nuclear $\mathrm{D}_{\max }{ }^{1}$ by examining a larger number of specimens of NHL and by including, in addition, specimens of reactive lymph nodes. There is good correlation of both $\mathrm{D}_{\max }$ and nuclear area with the Kiel histological subtype of the lymphomas, low-grade lesions having the lowest values of both of these parameters and high-grade NHL (especially immunoblastic lymphomas) having the largest values. Numerous criteria have been cited ${ }^{1213}$ in the past as aids to the distinction between reactive and neoplastic follicles; these have tended to be rather subjective. We have investigated the possibility that measurements of nuclear size might be of value; however nuclear $\mathrm{D}_{\max }$ and area are of similar magnitude in low-grade NHL and reactive nodes. Thus, the latter cannot be distinguished from the former on the basis of nuclear $\mathrm{D}_{\max }$ or area; this is unfortunate, as the differentiation between, for example, follicular centrocyticcentroblastic lymphomas and reactive follicular hyperplasia can prove to be very difficult on a subjective basis.

The correlation between mean nuclear $D_{\max }$ and mean area for each specimen is good, especially for reactive nodes and low-grade lymphomas. Clearly, there should be very close correlation between diameter and area for round or nearly round objects and it can be concluded that nuclei of such shape are predominant in nodes showing reactive change or 
low-grade NHL. In high-grade lymphomas, however, the correlation between these two parameters is rather less close, suggesting that the nuclei in these specimens are irregular or, at least, diverge significantly from perfect circularity. This conclusion is supported by our measurement of FF; the FF of an object is given by the simple relation:

$$
\mathrm{FF}=\frac{4 \pi \mathrm{A}}{\mathrm{P}^{2}}
$$

$\mathbf{A}=$ area of object.

$\mathbf{P}=$ perimeter of object.

A perfect circle has an FF of 1.0 and irregular or elliptical structures deviate from unity towards zero as their degree of circularity becomes less perfect. ${ }^{23}$ Our demonstration that high-grade lymphomas have lower FF values than low-grade NHL or reactive lymph nodes suggests that, in general, irregular or elliptical nuclei predominate (or are, at least, more frequent) in the high-grade lesions. However, the FF values for the different types of low-grade specimen and, for example, the two specimens of lymphoblastic high-grade lymphoma have FF values approaching $1 \cdot 0$. Nonetheless, the high $D_{\max }$ and area of nuclei in lymphoblastic lymphoma enables its discrimination as a high-grade lymphoma. Thus it would appear that, unlike nuclear $\mathrm{D}_{\max }$ and area, FF is a poor discriminator between high- and low-grade lymphomas and reactive lymph nodes. However, as the MOP-AMO ${ }_{3}$ gives values for FF in steps of $0 \cdot 1$, the poor discrimination given by this parameter may well be the result of false "compression" of the measured data.

The previously cited study of nuclear area by Abbott et $\mathbf{l}^{10}$ gave nuclear measurements considerably smaller than ours. This can readily be explained by virtue of several differences in technique between the two studies. For example, much thinner sections ( $1 \mu \mathrm{m}$ embedded in resin) were used by them than in our study where $4 \mu \mathrm{m}$ paraffin sections were used. Our studies also differed in the use of section thickness corrections. Moreover, we carefully programmed the MOP-AMO $\mathrm{A}_{3}$ to exclude very small structures and thus to diminish the effects of nonequatorial sectioning; consequently our measured values are inevitably greater than in the above $\stackrel{0}{\vec{*}}$ paper. Clearly, when dealing with areas, where $\frac{}{.}$ measurements are squared, such differences are $\overrightarrow{\vec{F}}$ exaggerated. The nuclear diameters in our current $\stackrel{5}{?}$ study are, in addition, in quite close accord with those measured in our earlier study, using the Zeiss $\frac{\bar{c}}{\bar{N}}$ Microvideomat. ${ }^{9}$

We wish to thank Mr J Gregory for his expert tech- ळ nical assistance and Miss Angela Wright for typing $\vec{O}$ the manuscript. The camera lucida was supplied by The Royal Society.

\section{References}

' Crocker J, Jones EL, Curran RC. Study of nuclear diameters in? non-Hodgkin's lymphoma. J Clin Pathol 1982;35:954-8.

${ }^{2}$ Round JM, Jones DA, Edwards RHT. A flexible microprocessor $\mathrm{C}_{0}$ system for the measurement of cell size. J Clin Pathol $\infty$ 1982;35:620-4.

${ }^{3}$ Crocker J, Jones EL, Curran RC. The form factor of alpha- naphthyl acetate esterase-positive cells in non-Hodgkin's lymphomas and reactive lymph nodes. J Clin Pathol 1983;36:303-6.

${ }^{4}$ Lennert K. Malignant lymphomas other than Hodgkin's disease. ${ }^{\stackrel{\rho}{+}}$ New York: Springer-Verlag, 1978.

${ }^{s}$ Crocker J, Curran RC. A quantitative study of theo immunoglobulin-containing cells in trephine samples of bone. marrow. J Clin Pathol 1981;34:1080-2.

${ }^{\circ}$ Crocker J, Jones EL, Curran RC. A quantitative study of $\alpha$-naphthyl acetate esterase-positive cells in non-Hodgkin's lymphomas and reactive lymph nodes. J Clin Patholo 1982;35:1066-8.

${ }^{7}$ Crocker J, Jones EL, Curran RC. A quantitative study of $\alpha$-naphthyl acetate esterase-positive cells in Hodgkin's disease. J Clin Pathol 1982;35:1301-6.

${ }^{8}$ Steer MW. Understanding cell structure. Cambridge, London, New York: Cambridge University Press, 1981.

${ }^{9}$ Crocker J, Curran RC. A study of nuclear diameters in lympk node imprints using the Zeiss Microvideomat. J Clin Pathol 1979;32:670-4.

${ }^{10}$ Abbott CR, Blewitt RW, Bird CC. Quantitative analysis of non-Hodgkin's lymphoma. J Clin Pathol 1982;35:135-8.

"Bennett MH, Farrer-Brown G, Henry K, Jellife AM… Classification of non-Hodgkin's lymphomas. Lancet 1974;ii:405-6.

12 Rappaport H. Tumours of the hematopoietic system. Atlas of tumour pathology, Section III, Fascicle 8. Washington DC: Armed Forces Institute of Pathology, 1966:426-31.

${ }^{13}$ Wright DH. The identification and classification of non-O Hodgkin's lymphoma: a review. Diagn Histopathol 1982;5:73-111.

Requests for reprints to: Dr J Crocker, Department of Pathology, The Medical School, University of Birminghamw B15 2TJ, England. 